\title{
PERAN KECERDASAN BUDAYA DAN KEPRIBADIAN TERHADAP PERILAKU KONSUMTIF ONLINE GENERASI MILENIAL YANG MERANTAU DI JAKARTA
}

\author{
Teguh Lesmana', Chyntia Monica Rarung² \\ 1Program Studi Psikologi Universitas Bunda Mulia Jakarta, Email: teguhlesmana73@gmail.com \\ 2Program Studi Psikologi Universitas Bunda Mulia Jakarta

\section{ABSTRACT: THE ROLE OF CULTURAL INTELLIGENCE AND PERSONALITY TOWARD ONLINE CONSUMTIVE BEHAVIOR OF MILLENNIAL GENERATION WHO WANDER IN JAKARTA}

This study aims to determine the role of cultural intelligence and personality on the online consumptive behavior of the millennial generation who have migrated in Jakarta. This research is a survey research design with non-experimental research types and involves three measuring instruments consisting of the Cultural Intelligence Measurement Scale (CIMS) to measure cultural intelligence, the Big Five Inventory 2 Short Form (BFI-2S) to measure personality characteristics and Consumptive Behavior Scale to measure the tendency of consumptive behavior. This study involved 303 participants who were millennials who had migrated to Jakarta. The results of this study indicate that cultural intelligence has a positive and significant correlation with consumptive behavior, where the higher the cultural intelligence possessed, the more it will increase the consumptive behavior of the participants. In addition, the results of subsequent studies showed that openness, agreeableness, and extraversion had a negative and significant correlation with consumptive behavior, while neuroticism had a positive and significant correlation with consumptive behavior. This study provides supporting data that cultural intelligence and personality in migrants can lead to consumptive behavior.

\section{Keywords: Personality, Cultural Intelligence, Consumtive Behavior}

Penelitian ini bertujuan untuk mengetahui peran kecerdasan budaya dan kepribadian terhadap perilaku konsumtif online generasi milenial yang merantau di Jakarta. Penelitian ini merupakan survey research design dengan jenis penelitian non eksperimental dan melibatkan tiga alat ukur yang terdiri atas Cultural Intelligence Measurement Scale (CIMS) untuk mengukur kecerdasan budaya, Big Five Inventory 2 Short Form (BFI-2S) untuk mengukur karakteristik kepribadian dan Skala Perilaku Konsumtif untuk mengukur kecenderungan perilaku konsumtif. Penelitian ini menggunakan teknik purposive sampling dan melibatkan 303 partisipan yang merupakan generasi milenial yang merantau di Jakarta dengan mayoritas partisipan berusia $20-25$ tahun (80.9\%). Hasil penelitian ini menunjukkan bahwa kecerdasan budaya berkorelasi positif dan signifikan dengan perilaku konsumtif, dimana semakin tinggi kecerdasan budaya yang dimiliki maka akan semakin meningkatkan perilaku konsumtif partisipan. Selain itu, hasil penelitian berikutnya menunjukkan bahwa openness, agreeableness, dan extraversionberkorelasi negatif dan signifikan dengan perilaku konsumtif, sementara neuroticism berkorelasi positif dan signifikan dengan perilaku konsumtif. Penelitian ini memberikan data pendukung bahwa kecerdasan budaya dan kepribadian pada perantau berperan dalam menentukan perilaku konsumtif.

Kata Kunci: Kepribadian, Kecerdasan Budaya, Perilaku Konsumtif

\section{PENDAHULUAN}

Menurut Sitorus (2016), riset yang digelar lembaga Independen Provetic tentang perilaku belanja konsumen menunjukkan para generasi milenial cenderung memiliki perilaku menabung untuk hal-hal yang bersifat konsumtif. Dalam riset berbasis media sosial selama 1 Desember 2015 - 31 Januari 2016, ditemukan sebanyak $41 \%$ dari 7.809 
Jurnal Psikologi Malahayati, Volume 2, No.2, September 2020: 57-71

PERAN KECERDASAN BUDAYA DAN KEPRIBADIAN TERHADAP PERILAKU
KONSUMTIF ONLINE GENERASI MILENIAL YANG MERANTAU DI JAKARTA

perbincangan mengenai alasan utama

masing. Ketika seorang anak milenial melihat

menabung demi keperluan konsumtif tersebut.

influencer idolanya menggunakan atau memiliki

Temuan lainnya, 38\% dari 7,757 responden

suatu barang, ia pun akan terdorong untuk ikut

masih menggunakan uang dari ibu atau orang

tua mereka dalam melakukan metode

pembayaran, selain penggunaan kartu debit

yang populer. Hal senada disampaikan oleh

hasil survei online yang digelar Facebook dan

Crowd DNA terhadap 1.000 responden berusia

13-24 tahun, yaitu ebanyak $79 \%$ responden

memikirkan mengenai pentingnya menabung,

tetapi hanya $62 \%$ yang benar-benar sudah

merencanakan masa depan mereka secara detil

(Lenggogini, 2016). Tuntutan yang tercipta dari

generasi milenial memacu kemajuan teknologi

dengan makin bertumbuhnya berbagai macam

aplikasi yang memungkinkan generasi milenial

untuk berbelanja dengan mudah dan cepat.

Menurut Prawira (2016), generasi

milenial ini memiliki perilaku konsumtif karena

tujuan utama dari mereka menabung adalah

untuk memenuhi tujuan jangka pendek yaitu dengan berbelanja, membeli tiket konser, ataupun melakukan travelling. Faktor-faktor yang mempengaruhi generasi milenial lebih konsumtif menurut Soebiakto (2018) yaitu: (1) peer pressure dari komunitas atau lingkaran pertemanan. Generasi milenial berperilaku konsumtif agar dapat menggunakan barang yang sama dengan teman sebayanya; (2) sebagian besar generasi milenial memiliki seorang influencer yang diikutinya lewat media sosial sebagai role model mereka, tergantung pada kegemaran dan ketertarikannya masingmembelinya. Endorsement lewat influencer media sosial ini bahkan merupakan cara pemasaran produk yang lebih efektif bagi generasi milenial, dibandingkan memasang iklan di televisi.

Berdasarkan hasil penelitian yang dilakukan oleh Hidayatullah, Waris, dan Devianti (2018) menunjukan bahwa variabel yang paling dominan pengaruhnya terhadap keputusan responden dalam menggunakan layanan online yaitu perilaku konsumtif, generasi milenial berperilaku konsumtif karena di era generasi milenial ini internet sudah sangat melekat dalam kehidupannya, internet ini bukan hanya digunakan untuk komunikasi atau mengkonsumsi konten melainkan juga segala jenis transaksi, dari transportasi, membeli makanan, jalan-jalan, hingga berbelanja pakaian dan kebutuhan sehari-hari. Berdasarkan hasil penelitian yang dilakukan oleh Moreno, Lafuente, Carreon, dan Moreno (2017), menunujukkan bahwa kaum milenial adalah pasar yang sangat menarik karena mereka tumbuh dalam lingkungan di mana teknologi menyediakan platform untuk personalisasi dan kepuasan langsung dalam semua aspek kehidupan. Akibatnya proses pembelian bagi kaum milenial menjadi sesuatu yang cenderung dinikmati dan kesetiaan terhadap merek sudah tidak jadi sesuatu yang penting lagi. Hasil penelitian tersebut juga Teguh Lesmana, Program Studi Psikologi Universitas Bunda Mulia. Jakarta. Email: teguhlesmana73@gmail.cmom

Chintya Monica Rarung, Program Studi Psikologi Universitas Bunda Mulia. Jakarta 
Jurnal Psikologi Malahayati, Volume 2, No.2, September 2020: 57-71

PERAN KECERDASAN BUDAYA DAN KEPRIBADIAN TERHADAP PERILAKU
KONSUMTIF ONLINE GENERASI MILENIAL YANG MERANTAU DI JAKARTA

menunjukkan bahwa generasi milenial

teknologi Optical Character Recogniton (OCR)

cenderung lebih cepat menghabiskan

pendapatan mereka melalui web khususnya

pada 6.123 responden (Tashandra, 2018).

Menurut Yasa (2018) berdasarkan

jejaring sosial atau media sosial, karena

generasi milenial lebih tertarik dengan iklan

virtual sebagai kupon atau diskon.

Survei terbaru lembaga riset Snapcart

di Januari 2018 mengungkapkan bahwa generasi milenial menjadi pembelanja terbanyak

di bidang e-commerce yakni sebanyak 50 persen (25-34 tahun). Mayoritas konsumen belanja online berdasarkan gender adalah wanita dengan jumlah mencapai 65 persen. Jika digabung dengan generasi Z (15-24 tahun) maka jumlah pembelanja dari generasi muda mencapai sekitar 80 persen. 25 persen sumber informasi berasal dari televisi dan 21 persennya dari iklan di sosial media seperti Facebook, Instagram atau Twitter. Sementara 24 persennya mendapat informasi soal ecommerce lewat promosi dari mulut ke mulut (word of mouth). Generasi milenial adalah generasi pertama yang melihat internet sebagai sebuah penemuan yang hebat dan mengubah segalanya. Sedangkan generasi Z merupakan generasi yang terlahir ketika internet dan sosial media sudah menjadi keseharian. Selain itu, millenial dan gen $z$ dianggap sebagai generasi yang sudah lekat dengan nafas digital, sehingga karakter digital memang sudah sangat melekat pada dua generasi tersebu, termasuk dalam perilaku berbelanja. Adapun survei ini dilakukan melalui Aplikasi Snapchat yang memanfaatkan hasil riset yang dilakukan oleh iPrice Indonesia menggunakan data Google Analytics untuk megnanalisis konsumen traktif dalam berbelanja online berdasarkan tempat tinggal ditemukan bahwa ada tujuh kota besar teraktif dalam berbelanja online di Indonesia, dari 2 juta pengguna iPrice di Jakarta ada $42 \%$ yang merupakan angka terbesar dari ketujuh kota yang aktif dalam berbelanja online. Sejalan dengan paragraph diatas menurut Khairuddin (2018), berdasarkan penemuan dari Priceza terdapat lima kota besar di Indonesia yang menjadi sumber utama dari kunjungan (traffic) ke berbagai tokoonline yaitu Jakarta, Surabaya, Medan, Bandung, dan Makasar dan yang menduduki posisi teratas yaitu Jakarta $41.94 \%$.

Menurut Hayyu (2019) tingginya laju pertumbuhan penduduk Indonesia dapat menyebabkan tingginya tingkat perpindahan penduduk dari desa ke kota, dikarenakan terbatasnya kesempatan dan lapangan pekerjaan serta maraknya alih fungsi lahan pertanian di desa membuat sebagian penduduk usia produktif memilih untuk mengadu nasib di kota. Salah satu yang menjadi faktor generasi milenial yang ada dipedesaan memilih untuk merantau ke Jakarta karena sedikitnya lapangan pekerjaan yang masih terbuka di kampung halaman selain dari pada itu upah atau gaji yang diterima ketika berada di Kota

Teguh Lesmana, Program Studi Psikologi Universitas Bunda Mulia. Jakarta. Email: teguhlesmana73@gmail.cmom

Chintya Monica Rarung, Program Studi Psikologi Universitas Bunda Mulia. Jakarta 
Jurnal Psikologi Malahayati, Volume 2, No.2, September 2020: 57-71

PERAN KECERDASAN BUDAYA DAN KEPRIBADIAN TERHADAP PERILAKU
KONSUMTIF ONLINE GENERASI MILENIAL YANG MERANTAU DI JAKARTA

terlebih di Jakarta lebih besar dibandingkan di pedesaaan (Alfido, 2014).

Menurut Harahap (2013), karakteristik urbanisasi yang terjadi di Jakarta hampir sama kota-kota besar didunia, yang menjadikan kota Jakarta sebagai salah satu kota besar di Indonesia yang menjadi target dan sasaran urbanisasi. Hal tesebut ditandai dengan meningkatnya jumlah penduduk kota yang terjadi setiap tahun. Menurut hasil penelitian Novitasani dan Handoyo (2014) beberapa mahasiswa urbanisasi yang pindah ke kota mengalami perubahan perilaku yang salah satunya menjadi lebih konsumtif dan kondisi tersebut terjadi karena proses pergeseran budaya dari daerah yang cenderung sederhana menjadi budaya kota yang identik dengan kehidupan yang serba konsumtif. Sejalan dengan pendapat diatas, salah satu faktor yang mempengaruhi perilaku konsumtif adalah pekerjaan dan lingkungan sosial, dimana seseorang akan berusaha membuat standar hidup yang sama dengan orang-orang yang ada disekelilingnya agar dapat diterima di lingkungan kerja atau lingkungan pergaulannya.

Dilansir dari Badan Pusat Statistik (2015), di Indonesia terdapat sekitar 1.128 suku bangsa yang masing-masing memiliki karakteristik tersendiri sehingga membuat Indonesia memiliki perbedaan yang membentuk keberagaman. Menurut Widyarini (2014) pada saat seseorang berinteraksi dengan individu yang memiliki latar belakang budaya yang berbeda maka orang itu dituntut untuk lebih keras dalam memahami, menerima serta menyesuaikan diri dengan lingkungan latar budaya yang berbeda dari individu tersebut, salah satu cara untuk meningkatkannya yaitu dengan mengenali dan mengembangkan kecerdasan budaya sehingga individu tersebut dapat memiliki kemampuan untuk memahami, berpikir, serta berperilaku secara efektif pada situasi-situasi yang mencirikan perbedaan antar budaya.

Menurut Hadawiah (2019) dalam penelitiannya mengakatakan proses interaksi yang dialami oleh mahasiswa di perantauan mengalami fase kekecewaan akibat dari banyaknya perbedaan antara kampung halaman dan kota perantauan sehingga memicu terjadinya pertukaran makna, persepsi dan perspektif, cara yang digunakan untuk data mengatasi perbedaan budaya tersebut adalah dengan berinteraksi dengan mahasiswa lokal dan juga berusaha lebih mengenal situasi dan kondisi dari lingkungan sekitar selain itu dengan adanya keterbiasaan maka dapat memecahkan masalah tersebut. Untuk dapat beradaptasi dengan budaya yang berbeda maka penting bagi seseorang untuk memiliki

Menurut Bhakti, Paradizsa, Alkaf \& Irwansyah (2018) dalam penelitiannya mengatakan kecerdasan budaya sangat penting untuk dimiliki oleh semua orang, terutama dalam masyarakat dengan keberagaman budaya yang ada, karena setiap harinya manusia akan bertemu atau berinteraksi dengan sesamanya yang memiliki perbedaan Teguh Lesmana, Program Studi Psikologi Universitas Bunda Mulia. Jakarta. Email: teguhlesmana73@gmail.cmom

Chintya Monica Rarung, Program Studi Psikologi Universitas Bunda Mulia. Jakarta 
Jurnal Psikologi Malahayati, Volume 2, No.2, September 2020: 57-71

PERAN KECERDASAN BUDAYA DAN KEPRIBADIAN TERHADAP PERILAKU
KONSUMTIF ONLINE GENERASI MILENIAL YANG MERANTAU DI JAKARTA

kebudayaan sehingga apabila seseorang

dan Costa (dalam Feist, Feist, \& Robert, 2018).

memiliki tingkat kecerdasan budaya yang tinggi

Dimensi dari Big Five Personality menurut dapat cepat atau lebih mudah baik dalam pekerjaan maupun di kehidupan sehari-hari ketika berinteraksi dengan sesamanya.

Penelitian ini bertujuan untuk mengetahui peran kepribadian dan kecerdasan budaya dalam menentukan perilaku konsumtif generasi milenial yang merupakan perantau di kota Jakarta. Kecerdasan budaya dapat menyebabkan generasi milenial yang merantau mengadopsi budaya di tempat baru untuk menjadi lebih mudah beradaptasi dengan tempat yang baru, namun hal ini kemungkinan dapat menyebabkan generasi milenial menjadi lebih konsumtif karena ingin cepat beradaptasi dengan tempat tinggalnya yang baru. Selain kecerdasan budaya, faktor lain yang kemungkinan dapat menentukan perilaku konsumtif generasi milenial adalah faktor kepribadian, sehingga dalam penelitian ini juga ingin menelusuri tipe kepribadian seperti apa yang lebih memungkinkan generasi milenial untuk memiliki perilaku konsumtif.

\section{Karakteristik Kepribadian}

Teori yang digunakan dalam menjelaskan kepribadian menggunakan The Five-Factor Theory atau yang sering dipanggil dengan The Big Five yang merupakan teori kepribadian dengan lima dimensi kepribadiannya yaitu, Openness, Conscientiousness, Extraversion, Agreeableness, dan Neuroticism oleh McCrae Burger (2019) adalah Neuroticism, Extraversion, Openness, Agreeableness, dan Conscientiousness.

Burger (2019) menjabarkan masingmasing dari dimensi tersebut, yaitu: (a) Neuroticism: Orang yang tinggi pada neuroticism cenderung untuk lebih mudah kecewa terhadap stressor harian dibandingkan dengan mereka yang lebih rendah pada dimensi ini dan lebih rentan terhadap kecemasan dan depresi. (b) Extraversion: seseorang yang tinggi pada karakteristik ini adalah orang yang sangat mudah bersosialisasi, cenderung lebih bersemangat, optimis, ramah, dan tegas. (c) Openness to experience: merujuk kepada keterbukaan kepada pengalaman dibandingkan dengan perasaan interpersonal, memiliki imajinasi yang aktif, kemauan untuk mempertimbangkan ide-ide yang baru, pemikiran yang berbeda, dan keingintahuan intelektual. (d) Agreeableness: Orang-orang yang tinggi dalam dimensi Agreeableness adalah orang yang suka menolong, dapat dipercaya, dan simpatik. (e) Conscientiousness: Dimensi Conscientiousness merujuk kepada bagaimana seseorang dapat mengontrol dan mendisiplinkan diri.

\section{Kecerdasan Budaya}

Livermore (2011) mendefinisikan kecerdasan budaya sebagai kemampuan untuk berfungsi secara efektif dalam berbagai konteks

Teguh Lesmana, Program Studi Psikologi Universitas Bunda Mulia. Jakarta. Email: teguhlesmana73@gmail.cmom

Chintya Monica Rarung, Program Studi Psikologi Universitas Bunda Mulia. Jakarta 
Jurnal Psikologi Malahayati, Volume 2, No.2, September 2020: 57-71

PERAN KECERDASAN BUDAYA DAN KEPRIBADIAN TERHADAP PERILAKU
KONSUMTIF ONLINE GENERASI MILENIAL YANG MERANTAU DI JAKARTA

budaya yang bervariasi. Kecerdasan Budaya merujuk pada kemampuan individu dalam memahami, berpikir dan berperilaku secara efektif dalam situasi-situasi yang bercirikan perbedaan antar budaya (Ang \& Van Dyne, 2008). Menurut Ang, Rockstuhl, dan Tan (2015), kecerdasan budaya ini mirip dengan kecerdasan sosial dan kecerdasan emosional. Kecerdasan sosial merujuk pada kemampuan untuk memahami dan mengelola hubungan sosial dengan orang lain. Kecerdasan emosional merupakan kemampuan dalam memahami dan menghadapi (mengelola) emosi diri sendiri dan emosi orang lain. Sedangkan kecerdasan budaya adalah kemampuan untuk memahami, mengelola, dan berhadapan dengan emosiemosi orang lain dalam konteks antar budaya. Dengan demikian, kecerdasan budaya merupakan salah satu bentuk spesifik dari kecerdasan interpersonal.

\section{Perilaku Konsumtif}

Menurut Kamus Besar Bahasa Indonesia (KBBI), perilaku konsumtif bersifat konsumsi yang hanya memakai dan tidak menghasilkan serta bergantung pada hasil produksi orang lain. Menurut Lubis (dalam Sumartono, 2002) perilaku konsumtif adalah suatu perilaku yang tidak lagi didasarkan pada pertimbangan yang rasional, melainkan karena adanya keinginan yang sudah tdak rasional lagi. Menurut Prishardoyo, Trimarwanto, dan Shodiqin (2005) perilaku konsumtif adalah perilaku yang suka membelanjakan uang dalam jumlah yang besar. Perilaku konsumtif menimbulkan dampak positif dan dampak negatif baik yang dirasakan oleh konsumen itu sendiri maupun oleh pihak lain. Perilaku konsumtif adalah suatu keadaan atau kecenderungan untuk membelanjakan seluruh pendapatan pada barang-barang konsumsi (Kardiman dkk, 2006).

\section{Dinamika Hubungan Kecerdasan Budaya dan Perilaku Konsumtif}

Berdasarkan penelitian yang dilakukan oleh Dumaz, Celik, dan Oruc (2011) diketahui bahwa tuntutan dan ajakan dari lingkungan merupakan hal yang mendorong seseorang untuk dapat melakukan pembelian barang agar dapat menyesuaikan diri dengan lingkungannya. Dalam konteks kecerdasan budaya, yang memiliki pengertian sebagai cara individu untuk memahami, berpikir, dan berperilaku efektif dalam situasi yang bercirikan perbedaan budaya (Ang, Rockstuhl, \& Tan, 2015) maka bila seseorang memiliki kecerdasan budaya yang baik, ada kemungkinan orang tersebut dapat lebih menerima masukan dan pendapat orang di lingkungannya untuk melakukan perilaku pembelian suatu barang. Selain itu berdasarkan penelitian lainnya mengenai kontribusi kecerdasan budaya dalam penggunaan internet ditemukan bahwa kecerdasan budaya mendukung proses secara tidak langsung dalam niat seseorang untuk menggunakan internet yang salah satu tujuannya untuk motivasi hedonis (Martinez,

Teguh Lesmana, Program Studi Psikologi Universitas Bunda Mulia. Jakarta. Email: teguhlesmana73@gmail.cmom

Chintya Monica Rarung, Program Studi Psikologi Universitas Bunda Mulia. Jakarta 
Jurnal Psikologi Malahayati, Volume 2, No.2, September 2020: 57-71

PERAN KECERDASAN BUDAYA DAN KEPRIBADIAN TERHADAP PERILAKU
KONSUMTIF ONLINE GENERASI MILENIAL YANG MERANTAU DI JAKARTA

Sabiote-Ortiz, \& Rey-Pino, 2018). Perilaku

konsumtif berdasarkan pengertiannya yang

menurut Prishardoyo, Trimarwanto, dan

Shodiqin (2005) merupakan perilaku yang suka membelanjakan uang dalam jumlah yang besar, dapat dikategorikan sebagai perilaku yang erat kaitannya dengan motivasi hedonis. Dengan demikian bila perilaku belanja online dalam penelitian ini dilakukan oleh pengguna internet yang memiliki kecerdasan budaya tinggi, maka ada kemungkinan untuk kecerdasan budaya tersebut dapat memicu perilaku konsumtif yang tinggi ketika belanja online.

\section{Dinamika Hubungan Karakteristik}

\section{Kepribadian dan Perilaku Konsumtif}

Berdasarkan penelitian sebelumnya

yang dilakukan oleh Widyaningrum dan Puspitadewi (2016) diketahui bahwa kepribadian ekstrovert memiliki tingkat perilaku konsumtif yang lebih tinggi dibanding kepribadian introvert karena berdasarkan karakteristiknya, kepribadian ekstroverttergolong orang yang berani mengambil resiko, termasuk dalam pembelian produk jika dibandingkan dengan orang yang memiliki tipe kepribadian introvert. Dalam penelitian lainnya yang dilakukan oleh Taufik, Prihartanti, dan Hamid (2019) ditemukan bahwa karakteristik kepribadian neuroticism, extraversion dan conscientiousness memiliki hubungan yang signifikan terhadap gaya hidup konsumtif, sementara openness to experience dan agreeableness tidak memiliki hubungan signifikan. Lebih lanjut ditemukan dalam penelitian tersebut (Taufik, Prihantanti, \& Hamid, 2019) bahwa neuroticism dan extraversionberhubungan positif sementara conscientiousness berhubungan negatif dengan gaya hidup hedonis. Dalam penelitian ini perilaku konsumtif merupakan perilaku yang suka membelanjakan uang dalam jumlah besar (Prishardoyo, Trimarwanto, \& SHodiqin, 2016) sehingga perilaku konsumtif diasumsikan oleh peneliti sebagai hal yang sama dengan gaya hidup hedonis.

\section{METODE}

Desain penelitian ini menggunakan survey research design dengan jenis penelitian menggunakan jenis penelitian non eksperimental. Menurut Gravetter \& Forzano (2018) survei research design yaitu sebuah penelitian yang menggunakan survei untuk mendapatkan kelompok gambaran dari individu tertentu. Penelitian ini dilakukan sejak bulan Januari sampai April 2020 di Jakarta dengan melibatkan sampel sebanyak 303 orang yang masuk dalam generasi milenial (berusia 20-40 tahun). Sampel diperoleh dengan menggunakan teknik purposive sampling dengan kriteria subjek: (a) berusia antara 20-40 tahun, (b) merupakan perantau yang berasal dari luar Jakarta, (c) terbiasa melakukan belanja online minimal seminggu sekali, (d) memiliki penghasilan atau pendapatan yang dapat digunakan untuk belanja online.

Pengambilan data dilakukan dengan menyebarkan skala pengukuran. Skala yang

Teguh Lesmana, Program Studi Psikologi Universitas Bunda Mulia. Jakarta. Email: teguhlesmana73@gmail.cmom

Chintya Monica Rarung, Program Studi Psikologi Universitas Bunda Mulia. Jakarta 
Jurnal Psikologi Malahayati, Volume 2, No.2, September 2020: 57-71

PERAN KECERDASAN BUDAYA DAN KEPRIBADIAN TERHADAP PERILAKU

KONSUMTIF ONLINE GENERASI MILENIAL YANG MERANTAU DI JAKARTA

digunakan yaitu: (1) Cultural Intelligence ( $a=.656)$, $(\mathrm{d})$ neuroticism $(a=.641)$, (e)

Measurement Scale (CIMS) milik Ang dan Dyne openness to experience $(\alpha=.658)$. Untuk alat

(2008) yang sudah diadaptasi ke dalam bahasa ukur skala perilaku konsumtif yang dibuat oleh

Indonesia untuk mengukur kecerdasan budaya, peneliti memiliki reliabilitas yang baik, dengan

(2) Big Five Inventory 2 Short Form(BFI-2S)

milik Soto dan John (2017) yang sudah

diadaptasi ke dalam bahasa Indonesia, (3)

Skala Perilaku Konsumtif yang dibuat oleh

peneliti sendiri berdasarkan teori perilaku

konsumtif menurut Sumartono (2002).

Reliabilitas alat ukur CIMS tergolong baik ( $\mathrm{a}$ $=.902$ ), kemudian untuk alat ukur BFI-2S

tergolong cukup baik dengan reliabilitas

cronbach alpha masing-masing aspek sebagai

berikut: (a) extraversion ( $a=.674)$, (b)

nilai cronbach alpha sebesar 936 .

Penelitian dilakukan dengan

menyebarkan kuesioner melalui form online google.doc dan selanjutnya data yang terkumpul diolah dengan menggunakan program SPSS versi 21. Dalam penelitian ini, selain menanyakan data penelitian yang berupa skala pengukuran, peneliti juga menanyakan data demogratis (usia, jenis kelamin, asal daerah, pendidikan, pendapatan, dan kebiasaan agreeableness ( $\alpha=.603)$, (c) conscientiousness

berbelanja).

\section{HASIL}

Mayoritas responden berjenis kelamin perempuan (70.3\%), berusia 20-25 tahun (80.9\%), berpendidikan S1 (58.4\%), daerah asal Sulawesi $(71.9 \%)$, dan berpendapatan kurang dari 3 juta dalam sebulan (68.3\%). Gambaran lengkap data demografis responden partisipan dapat dilihat pada Tabel 1

Teguh Lesmana, Program Studi Psikologi Universitas Bunda Mulia. Jakarta. Email: teguhlesmana73@gmail.cmom

Chintya Monica Rarung, Program Studi Psikologi Universitas Bunda Mulia. Jakarta 
Jurnal Psikologi Malahayati, Volume 2, No.2, September 2020: 57-71

PERAN KECERDASAN BUDAYA DAN KEPRIBADIAN TERHADAP PERILAKU

KONSUMTIF ONLINE GENERASI MILENIAL YANG MERANTAU DI JAKARTA

\section{Tabel 1}

Gambaran Demogratis Responden Partisipan

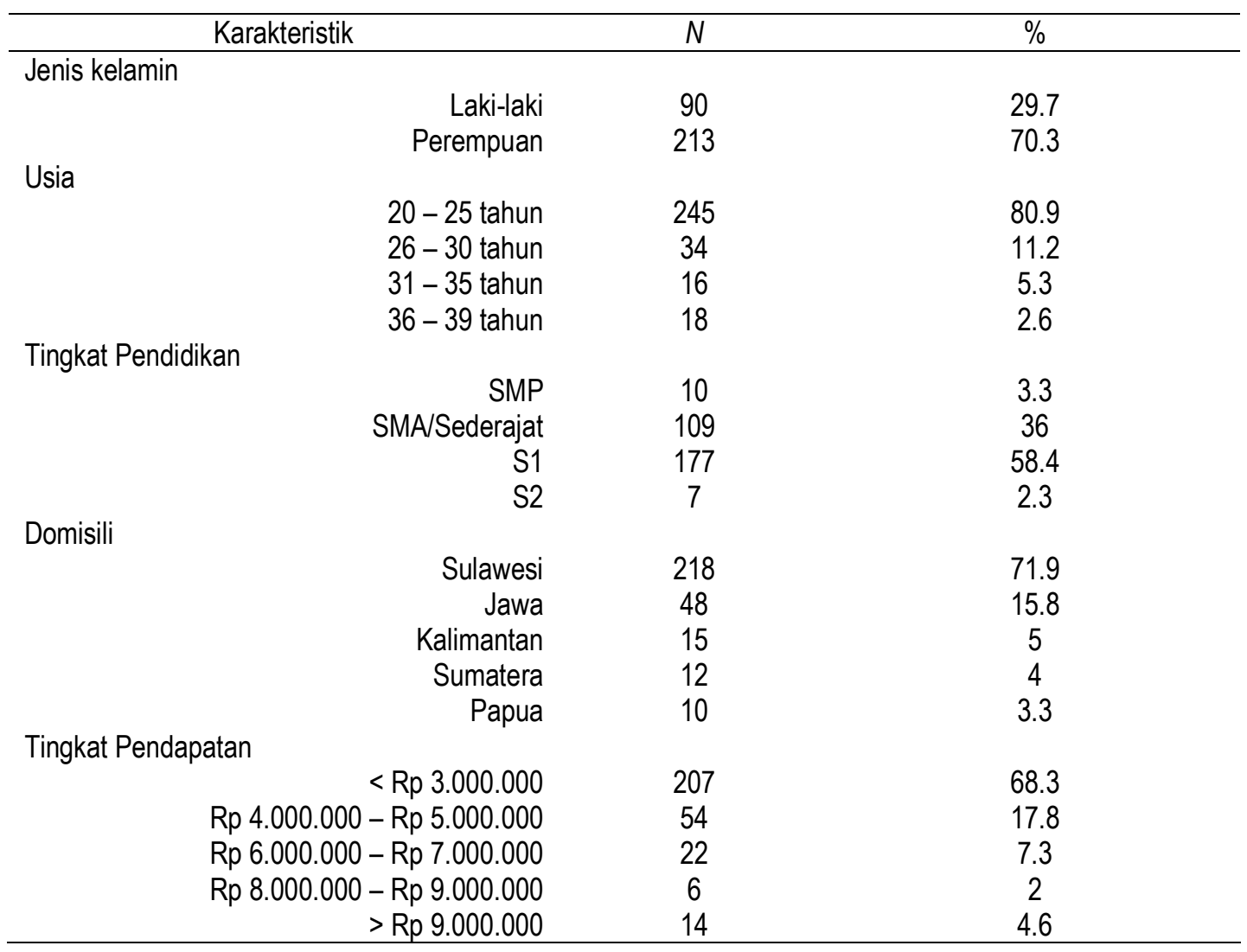

Berdasarkan uji normalitas data, diketahui bahwa variabel kecerdasan budaya, perilaku konsumfit, dan kelima karakteristik kepribadian memiliki distribusi data tidak normal, sehingga uji korelasi yang digunakan adalah uji korelasi spearman. Berdasarkan uji korelasi diketahui bahwa kecerdasan budaya berkorelasi positif dan signifikan dengan perilaku konsumtif partisipan. Beberapa karakteristik kepribadian juga diketahui berkorelasi negatif dan signifikan dengan kecerdasan budaya yaitu agreeableness, extraversion, dan openness to experience. Sementara karakteristik keprbiadian neuroticism berkorelasi positif dan signifikan dengan perilaku konsumtif. Data analisis lengkap dari analisis korelasi variabel dapat dilihat pada Tabel 2.

Teguh Lesmana, Program Studi Psikologi Universitas Bunda Mulia. Jakarta. Email: teguhlesmana73@gmail.cmom

Chintya Monica Rarung, Program Studi Psikologi Universitas Bunda Mulia. Jakarta 
Jurnal Psikologi Malahayati, Volume 2, No.2, September 2020: 57-71

PERAN KECERDASAN BUDAYA DAN KEPRIBADIAN TERHADAP PERILAKU

KONSUMTIF ONLINE GENERASI MILENIAL YANG MERANTAU DI JAKARTA

Tabel 2.

Analisis Korelasi Variabel

\begin{tabular}{lcccc}
\hline Variable & $\mathrm{M}$ & $\mathrm{SD}$ & 1 & 2 \\
\hline 1. Kecerdasan Budaya & 73.44 & 9.97 & & \\
2. Perilaku Konsumtif & 75.06 & 17.32 & $.148^{* *}$ & \\
3. Agreeableness & 7.10 & 1.85 & & $-.249^{* *}$ \\
4. Neuroticism & 14.15 & 3.42 & & $.149^{* *}$ \\
5. Extraversion & 16.58 & 3.27 & & $-.172^{* *}$ \\
6. Openness & 13.89 & 2.90 & & $-.348^{* *}$ \\
7. Conscientiousness & 16.95 & 3.02 & & .069 \\
\hline${ }^{* *} p<.01$ & & & &
\end{tabular}

DISKUSI

Berdasarkan hasil analisis data yang telah dilakukan, hasil korelasi menunjukkan adanya hubungan posit yang signifikan antara tingkat kecerdasan budaya dengan perilaku konsumtif generasi milenial perantau. Hasil korelasi positif ini dapat diartikan bahwa semakin tinggi kecerdasan budaya dari seorang perantau maka semakin tinggi pula kecenderungan untuk berperilaku konsumtif, begitu juga sebaliknya, di mana ketika semakin tinggi tingkat perilaku konsumtif maka semakin tinggi juga kecerdasan budaya seorang perantau di Jakarta.Kecerdasan Budaya merujuk pada kemampuan individu dalam memahami, berpikir dan berperilaku secara efektif dalam situasi-situasi yang bercirikan perbedaan antar budaya (Ang \& Dyne 2008). Pergeseran Budaya dari daerah yang cenderung sederhana menjadi budaya perkotaan (Jakarta), bukan hanya mengubah cara berpakaian seseorang namun pola kebiasaan Generasi Milenial Perantau juga mengalami perubahan, salah satu faktor pendorong adalah teman sebaya selain itu setiap individu memiliki rasa ingin tahu tentang suatu hal (Novitasani \& Handoyo, 2014). Hasil dalam penelitian ini sesuai dengan hasil penelitian yang dilakukan oleh Dumaz, Celik, dan Oruc (2011) bahwa tuntutan dan ajakan dari lingkungan merupakan hal yang mendorong seseorang untuk dapat melakukan pembelian barang agar dapat menyesuaikan diri dengan lingkungannya, sehingga seseorang dengan kecerdasan budaya yang tinggi akan lebih mungkin mengadopsi kebiasaan lingkungan barunya untuk ikut menjadi konsumtif. Hasil hubungan positif dalam penelitian ini juga didukung oleh penelitian sebelumnya dari Martinez, Sabiote-Ortiz, dan Rey-Pino (2018) yang menjelaskan bahwa seseorang dengan kecerdasan budaya tinggi dapat memiliki kecenderungan untuk menggunakan internet yang tujuannya untuk motivasi hedonis. Dalam penelitian ini, perilaku belanja online merupakan perilaku yang menggunakan internet, sehingga seseorang yang memiliki kecerdasan budaya

Teguh Lesmana, Program Studi Psikologi Universitas Bunda Mulia. Jakarta. Email: teguhlesmana73@gmail.cmom

Chintya Monica Rarung, Program Studi Psikologi Universitas Bunda Mulia. Jakarta 
Jurnal Psikologi Malahayati, Volume 2, No.2, September 2020: 57-71

PERAN KECERDASAN BUDAYA DAN KEPRIBADIAN TERHADAP PERILAKU
KONSUMTIF ONLINE GENERASI MILENIAL YANG MERANTAU DI JAKARTA

tinggi dapat lebih mungkin melakukan belanja online dengan tujuan untuk bersenang-senang.

Pada hubungan karakteristik kepribadian dengan perilaku konsumtif ditemukan bahwa agreeableness, extraversion, dan openness to experiencememiliki hubungan negatif dan signifikan yang artinya semakin tinggi ketiga kecenderungan karakteristik kepribadian tersebut akan menyebabkan rendahnya perilaku konsumtif partisipan. Hubungan yang negatif dari agreeableness dengan perilaku konsumtif didukung oleh hasil penelitian sebelumnya dari Ksendzova, Iyer, Hill, Wojcik, dan Howell (2015) yang menjelaskan bahwa seseorang 6yang kurang memiliki agreeableness akan cenderung mencari pemenuhan kebutuhan dirinya secara berlebihan, hal ini disebabkan karena orang dengan agreeableness yang rendah hanya mementingkan dirinya sendiri dan hal itu mengarahkannya untuk menjadi berlebihan dalam mengejar pemuasan kebutuhan pribadi yang akhirnya mengarah ke konsumsi maladaptif. Hubungan yang negatif dari extraversion dengan perilaku konsumtif dalam belanja online merupakan sesuatu yang berlawanan dengan beberapa hasil penelitian sebelumnya (Tsao \& Chang, 2010; Rehman \& Manjur, 2018; Farid \& Ali, 2018) yang menemukan bahwa extraversion memiliki hubungan yang positif dengan perilaku konsumtif, namun terdapat juga penelitian sebelumnya (Quintelier, 2014) yang menemukan bahwa extraversion dapat memiliki hubungan negatif dengan perilaku konsumtif karena tidak semua orang dengan kecenderungan ekstravert di usia muda memiliki keinginan untuk aktif membeli barang, namun keinginan yang ada pada orang di usia muda dengan kepribadian ekstravert adalah untuk berinteraksi dan bersosialisasi dengan orang lain membicarakan barang yang ingin dibeli. Dalam penelitian ini mayoritas responden berusia 20-25 tahun sehingga responden dalam penelitian ini yang memiliki kepribadian ekstravert kemungkinan lebih aktif membicarakan barang yang ingin dibeli dibanding aktif dalam perilaku belanja online tersebut.

Hubungan yang negatif dari openness to experience dengan perilaku konsumtif didukung oleh hasil penelitian sebelumnya dari Ksendzova, Iyer, Hill, Wojcik, dan Howell (2015) yang menjelaskan bahwa seseorang yang kurang memiliki kepribadian openness to experience akan cenderung mengabaikan kesempatan untuk mencoba hal baru dalam membeli suatu barang dan lebih mengejar hal yang bersifat instan dan bukan suatu hal yang baru dalam mengejar pemuasan kebutuhan pribadi yang cenderung bersifat konsumsi maladaptif. Dalam penelitian ini indikator perilaku konsumtif yang diteliti diantaranya terdiri atas 8 indikator yaitu: (a) membeli produk karena iming-iming hadiah, (b) membeli produk karena kemasannya menarik, (c) membeli produk demi menjaga penampilan diri dan gengsi, (d) membeli produk atas dasar

Teguh Lesmana, Program Studi Psikologi Universitas Bunda Mulia. Jakarta. Email: teguhlesmana73@gmail.cmom

Chintya Monica Rarung, Program Studi Psikologi Universitas Bunda Mulia. Jakarta 
Jurnal Psikologi Malahayati, Volume 2, No.2, September 2020: 57-71

PERAN KECERDASAN BUDAYA DAN KEPRIBADIAN TERHADAP PERILAKU
KONSUMTIF ONLINE GENERASI MILENIAL YANG MERANTAU DI JAKARTA

pertimbangan harga (bukan atas dasar manfaat dan kegunaannya), (e) membeli produk hanya sekedar menjaga simbolis status, (f) memakai sebuah produk karena unsure komformitas terhadap model yang mengiklankan produk, (g) munculnya penilaian bahwa membeli produk dengan harga mahal akan menimbulkan rasa percaya diri yang tinggi, (h) mencoba lebih dari dua produk sejenis (merk berbeda). Dari indikator yang digunakan dalam penelitian ini dapat disimpulkan jika seseorang memiliki kepribadian openness to experience yang rendah maka orang tersebut akan lebih kecil kemungkinan untuk mencoba membeli produk saat belanja online dengan indikator yang sudah dijelaskan, khususnya mencoba produk dengan merek berbeda.

Hasil hubungan yang positif dari karakteristik neuroticism dengan perilaku konsumtif menunjukkan bahwa semakin tinggi kecenderungan kepribadian neurotisme yang dimiliki seseorang maka akan semakin tinggi perilaku konsumtif partisipan. Hasil ini didukung oleh hasil penelitian sebelumnya dari Huang dan Yang (2010) yang menemukan bahwa kepriabdian neurotis dengan emosi negatifnya akan cenderung lebih memilih untuk berbelanja online dibanding harus berbelanja di dunia nyata karena memiliki motivasi untuk membatasi hubungan sosial. Dalam penelitian ini, perilaku konsumtif yang diteliti merupakan perilaku konsumtif yang dilakukan dalam berbelanja online, sehingga partisipan yang memiliki kecenderungan neurotis lebih tinggi akan cenderung lebih memiliki perilaku konsumtif dalam hal belanja online.

Hal yang menjadi keterbatasan dalam penelitian ini adalah peneliti tidak menanyakan frekuensi atau intensitas perilaku belanja online yang dilakukan oleh para partisipan, sehingga peneliti tidak mengetahui secara pasti apakah semua partisipan dalam penelitian memiliki kebiasaan belanja online yang sama intensitasnya. Keterbatasan lain dari penelitian ini adalah peneliti tidak menanyakan informasi mengenai lama waktu partisipan sudah merantau di Jakarta, sehingga para partisipan dalam penelitian ini tidak diketahui masingmasing berapa lama sudah merantau di Jakarta.

\section{SIMPULAN DAN SARAN}

Hasil penelitian menunjukkan bahwa kecerdasan budaya dan karakteristik kepribadian neuroticism memiliki hubungan positif yang signifikan dengan perilaku konsumtif. Sementara karakteristik kepribadian agreeableness, extraversion, dan openness to experience memiliki hubungan negatif yang signifikan dengan perilaku konsumtif.

Saran untuk peneliti selanjutnya adalah sebaiknya peneliti menanyakan frekuensi atau intensitas perilaku belanja online para partisipan agar dapat diketahui lebih jelas kebiasaan perilaku belanja online para partisipan dan penelitian berikutnya juga dapat menanyakan lama waktu merantau para masing-masing partisipan untuk didapatkan data partisipan yang lebih homogen karakteristiknya. Untuk

Teguh Lesmana, Program Studi Psikologi Universitas Bunda Mulia. Jakarta. Email: teguhlesmana73@gmail.cmom

Chintya Monica Rarung, Program Studi Psikologi Universitas Bunda Mulia. Jakarta 
Jurnal Psikologi Malahayati, Volume 2, No.2, September 2020: 57-71

\section{PERAN KECERDASAN BUDAYA DAN KEPRIBADIAN TERHADAP PERILAKU KONSUMTIF ONLINE GENERASI MILENIAL YANG MERANTAU DI JAKARTA}

penelitian berikutnya dapat meneliti variabel

yang berhubungan dengan kecerdasan budaya seperti kecerdasan emosi dan kecerdasan sosial untuk diteliti dengan perilaku konsumtif karena menurut Ang, Rockstuhl, dan Tan (2015), kecerdasan budaya ini mirip dengan kecerdasan sosial dan kecerdasan emosional.

\section{Daftar Pustaka}

Alfiedo. (2014). Ini Dia Alasan Orang-orang Merantau Ke Jakarta Dan Kota Besar Lainnya. Diakses dari : https://alfido.com/2014/07/31/ini-diaalasan-orang-orang-merantau-kejakarta-dan-kota-besar-lainnya/

Ang, S., Rockstuhl, T., \& Tan, M. L. (2015). Cultural intelligence and competencies. International encyclopedia of social and behavioral sciences, 2, 433-439.

Ang, S., \& Van Dyne, L. (2008). Handbook of cultural intelligence: Theory, measurement, and applications. Armonk: ME Sharpe.

Burger, J.M.. (2019). Personality (10th Ed). Boston: Cengage Learning, Inc.

Badan Pusat Statistik (2015) Mengulik Data Suku Di Indonesia. Diakses dari: https://www.bps.go.id/news/2015/11/18 /127/mengulik-data-suku-diindonesia.html

Bhakti, A. H., Paradizsa, I., Alkaf, I., \& Irwansyah, I. (2018). Pengaruh Media Sosial Terhadap Pengalaman Multikultural dan Kecerdasan Budaya. Metakom, 2(1).
Durmaz, Y., Celik, M., \& Oruç, R. (2011). The impact of cultural factors on the consumer buying behaviors examined through an empirical study. International Journal of Business and Social Science, 2(5), 109-114.

Gravetter, F. J., \& Forzano, L. A. B. (2018). Research methods for the behavioral sciences. Cengage Learning.

Farid, D. S., \& Ali, M. (2018). Effects of personality on impulsive buying behavior: Evidence from a developing country.

Feist, J., Feist, G. J., \& Roberts, T. A. (2018). Theories of personality (Ninth edit).

Hadawiah, H. (2019). Fenomena (Gegar Budaya) Pada Mahasiswa Perantauan Di Universitas Muslim Indonesia. AlMUNZIR, 12(1), 149-164.

Harahap, F. R. (2013). Dampak urbanisasi bagi perkembangan kota di Indonesia. Society, 1(1), 35-45.

Hayy, A. M. N. F. (2019). Mengelola Urbanisasi Untuk Pertumbuhan Ekonomi. Diakses Dari :https://news.detik.com/kolom/d4504255/mengelola-urbanisasi-untukpertumbuh an-ekonomi

Hidayatullah, S., Waris, A., \& Devianti, R. C. (2018). Perilaku generasi milenial dalam menggunakan aplikasi Go-food. Jurnal Manajemen dan kewirausahaan, 6(2), 240-249.

Huang, J. H., \& Yang, Y. C. (2010). The relationship between personality traits and online shopping motivations. Social Behavior and Personality: an international journal, 38(5), 673-679.

Khairuddin I. (2018). 5 Kota Ini Paling Banyak Jumlah Pembelanja Online. Diakses dari: https://selular.id/2018/06/5-kotaini-paling-banyak-jumlah-pembelanjaonline/

Teguh Lesmana, Program Studi Psikologi Universitas Bunda Mulia. Jakarta. Email: teguhlesmana73@gmail.cmom

Chintya Monica Rarung, Program Studi Psikologi Universitas Bunda Mulia. Jakarta 
Jurnal Psikologi Malahayati, Volume 2, No.2, September 2020: 57-71

\section{PERAN KECERDASAN BUDAYA DAN KEPRIBADIAN TERHADAP PERILAKU \\ KONSUMTIF ONLINE GENERASI MILENIAL YANG MERANTAU DI JAKARTA}

Ksendzova, M., lyer, R., Hill, G., Wojcik, S. P., \& Howell, R. T. (2015). The portrait of a hedonist: The personality and ethics behind the value and maladaptive pursuit of pleasure. Personality and Individual Differences, 79, 68-74.

Lenggogini S. (2017). Menangkap Gairah Wisata Milenial. Diakses Dari :https://news. detik.com/kolom/d3778270/menangkap-gairah-wisata$\underline{\text { milenial }}$

Livermore, D. A. (2009). Cultural intelligence (youth, family, and culture): Improving your $C Q$ to engage our multicultural world. Baker Academic.

Martínez, A. L. C., Sabiote-Ortiz, C. M., \& ReyPino, J. M. (2018). The influence of cultural intelligence on intention of internet use. Spanish Journal of Marketing-ESIC.

Moreno, F. M., Lafuente, J. G., Carreón, F. Á., \& Moreno, S. M. (2017). The characterization of the millennials and their buying behavior. International Journal of Marketing Studies, 9(5), 135144.

Novitasani, L. (2014). Perubahan Gaya Hidup Konsumtif Pada Mahasiswa Urban di UNESA. Paradigma, 2(3).

Prawira A. E. (2016). Ini Dia Motivasi Generasi Milenial Belanja. Diakses Dari :https://www.liputan6.com/health/read/2 483465/ini-dia-motivasi-generasimilenial-belanja

Prishardoyo, B., Trimarwanto, A., \& Shodiqin, S. P. (2005). Pelajaran Ekonomi SMP kelas 2. Grasindo.

Quintelier, E. (2014). The influence of the Big 5 personality traits on young people's political consumer behavior. Young Consumers.
Rehman, H. U., \& Manjur, K. I. (2018). Effects of Personality traits (Neuroticism, Agreeableness, Extraversion, Conscientiousness) on online impulse buying: Moderating role of hedonic motivation.

Sitorus R. (2016). Riset Perilaku Konsumen : Generasi Milenial Menabung untuk Konsumtif. Diakses Dari :https://kabar24.bisnis.com/read/20160 307/79/525973 /riset-perilakukonsumen-generasi-milenialmenabung-untuk-konsumtif

Soebiakto, B. (2018). Alasan Generasi milenial Lebih Konsumtif. Diakses dari https://www.cnnindonesia.com/gayahidup/20180418215055-282291845/alasan-generasi-milenial-lebihkonsumtif

Soto, C. J., \& John, O. P. (2017). Short and extra-short forms of the Big Five Inventory-2: The BFI-2-S and BFI-2$\mathrm{XS}$. Journal of Research in Personality, 68, 69-81.

Sumartono. (2002). Terperangkap dalam iklan (meneropong imbas pesan iklan televisi). Bandung: Alfabeta

Tashandra N.(2018). Riset : 80 persen Konsumen Belanja Online Orang Muda dan Wanita. Diakses dari :https://lifestyle.kompas.com/read/2018 /03/22/155001 820/80-persenkonsumen-belanja-online-orang-mudadan-wanita

Taufik, T., Prihartanti, N., \& Hamid, H. S. A. (2019). Neuroticism, extraversion and conscientiousness as predictors of the hedonistic lifestyle.

Tsao, W. C., \& Chang, H. R. (2010). Exploring the impact of personality traits on online shopping behavior. African Journal of Business Management, 4(9), 1800-1812.

Teguh Lesmana, Program Studi Psikologi Universitas Bunda Mulia. Jakarta. Email: teguhlesmana73@gmail.cmom

Chintya Monica Rarung, Program Studi Psikologi Universitas Bunda Mulia. Jakarta 
Jurnal Psikologi Malahayati, Volume 2, No.2, September 2020: 57-71

PERAN KECERDASAN BUDAYA DAN KEPRIBADIAN TERHADAP PERILAKU

KONSUMTIF ONLINE GENERASI MILENIAL YANG MERANTAU DI JAKARTA

Widyaningrum, S., \& Puspitadewi, N. W. S. (2016). Perbedaan Perilaku Konsumtif Ditinjau dari Tipe Kepribadian Pada Siswa Sekolah Menengah Atas. Jurnal Psikologi Teori dan Terapan, 6(2), 102106.

Widyarini (2014). Empat Faktor Kecerdasan Budaya Untuk Meningkatkan Keterampilan Initerpersonal. Diakses dari: $\quad$ https://bppk.kemenkeu.go.id /content/berita/balai-diklat-keuangan-

malang-empat-faktor-kecerdasan-

budaya-un tuk-meningkatkanketerampilan-interpersonal-2019-11-05$\underline{\text { a85cab971 }}$

Yasa A. (2018). Ini Kota-kota Teraktif Belanja Daring di Indonesia Ketika Bulan Ramadan. Diakses dari https://ekonomi.bisnis.com/read/20180 620/12/807626/ini-kota-kota-teraktifbelanja-daring-di-indonesia-ketikaperiode-ramadan

Teguh Lesmana, Program Studi Psikologi Universitas Bunda Mulia. Jakarta. Email: teguhlesmana73@gmail.cmom

Chintya Monica Rarung, Program Studi Psikologi Universitas Bunda Mulia. Jakarta 